\title{
Implementation of Boolean Functions through Multiplexers with the Help of Shannon Expansion Theorem
}

\author{
Saurabh Rawat \\ Graphic Era University. \\ Dehradun
}

\author{
Anushree Sah \\ The University of Greenwich, \\ London, UK,
}

\author{
Sumit Pundir \\ Graphic Era University. \\ Dehradun
}

\begin{abstract}
Implementation of Boolean function through multiplexer can be done by various multiplexers depending upon the select lines. Implementation of Boolean functions can be done by various methods, but in this particular paper stress is more on multiplexers. Through Shannon expansion theorem,it is easy for us to implement the Boolean functions in a simpler way. Upto three variables, can be handled by multiplexers, and above that we have taken aid of look out table, and how it uses multiplexers in their operations.
\end{abstract}

\section{Keywords}

Multiplexers, $2 \times 1,4 \times 1,8 \times 1$, multiplexers, Shannon Theorem..

\section{Multiplexer}

A multiplexer circuit has a number of data inputs, one or more select inputs and one output. It passes the signal value on one of the data inputs to the output. Data input is selected by the values of the select inputs. Select input $S$, chooses as the output of the multiplexer either input $\mathrm{x}_{0}$ or $\mathrm{x}_{1}$. Multiplexer's functionality can be described in the form of a truth table.

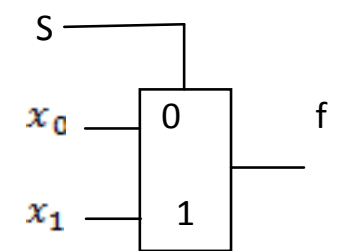

1.1 Graphic symbol

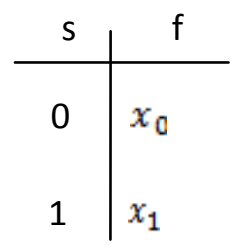

1.2 truth table

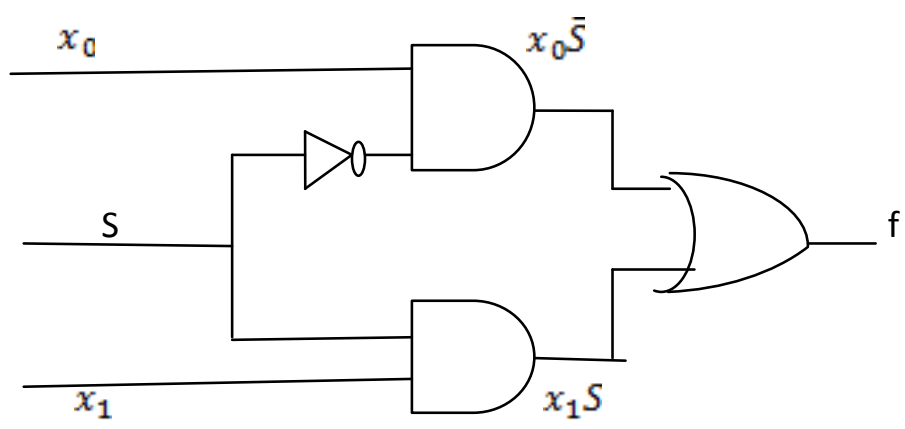

1.3 Sum of products circuit
A 2 to 1 Multiplexer $\left(\mathrm{f}=x_{0} \bar{S}+x_{1} S\right)$

and 4 to 1 multiplexer have four data inputs $\mathrm{x}_{0}, \mathrm{x}_{1}, \mathrm{x}_{2}, \& \mathrm{x}_{3}$ and two select inputs $\mathrm{S} 1$ and $\mathrm{S} 0$. The two bit number represented by S1S0 select one of the data input as output of the multiplexer.

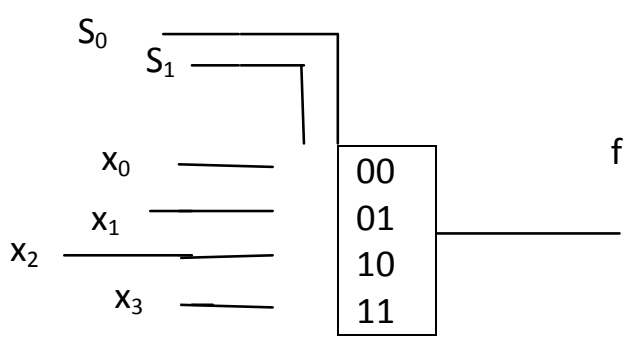

1.4 Graphic symbol

\begin{tabular}{|l|l|l|}
\hline \multicolumn{1}{|c|}{$\mathbf{S}_{\mathbf{1}}$} & $\mathbf{S}_{\mathbf{2}}$ & \multicolumn{1}{|c|}{$\mathbf{f}$} \\
\hline 0 & 0 & $\mathbf{x}_{\mathbf{0}}$ \\
\hline 0 & 1 & $\mathbf{x}_{\mathbf{1}}$ \\
\hline 1 & 0 & $\mathbf{x}_{\mathbf{2}}$ \\
\hline 1 & 1 & $\mathbf{x}_{\mathbf{3}}$ \\
\hline
\end{tabular}

1.5 Truth table 


\begin{tabular}{|l|l|l|l|l|}
\hline Minterms & $A_{1}$ & $A_{2}$ & $A_{3}$ & f \\
\hline 0 & 0 & 0 & 0 & 0 \\
\hline 1 & 0 & 0 & 1 & 0 \\
\hline 2 & 0 & 1 & 0 & 0 \\
\hline 3 & 0 & 1 & 1 & 1 \\
\hline 4 & 1 & 0 & 0 & 0 \\
\hline 5 & 1 & 0 & 1 & 1 \\
\hline 6 & 1 & 1 & 0 & 1 \\
\hline 7 & 1 & 1 & 1 & 1 \\
\hline
\end{tabular}

\subsubsection{Truth table}

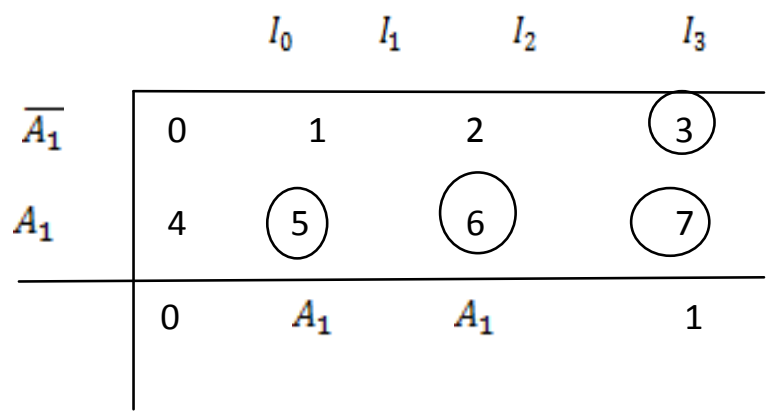

2.2.2 Multiplexer Implementation

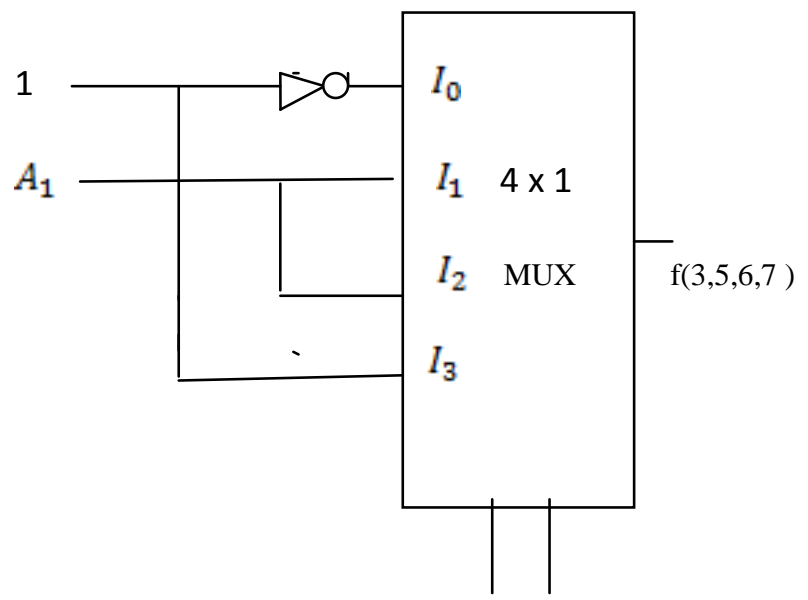

$A_{2} A_{3}$

2.2.3 4x1 Multiplexer implementation (b) $\mathrm{f}\left(\mathrm{A}_{1}, \mathrm{~A}_{2}, \mathrm{~A}_{3}\right)=\Sigma(3,5,6,7)$

If LSB i.e. $A_{3}$ is used as single variable and $A_{1}, A_{2}$ as select inputs

\begin{tabular}{|l|l|l|l|ll|l|}
\hline Minterm & $A_{1}$ & $A_{2}$ & $A_{3}$ & & $\mathrm{f}$ & \\
\hline 0 & 0 & 0 & 0 & 0 & & \\
\hline & 0 & 0 & 1 & 0 & $\mathrm{f}=0$ & $I_{0}$ \\
\hline 2 & 0 & 1 & 0 & 0 & & \\
\hline 5 & 0 & 1 & 1 & 1 & $\mathrm{f}=A_{3}$ & $I_{1}$ \\
\hline 6 & 1 & 0 & 0 & 0 & & \\
7 & 1 & 0 & 1 & 1 & $\mathrm{f}=A_{3}$ & $I_{2}$ \\
\hline
\end{tabular}

\subsubsection{Truth table}

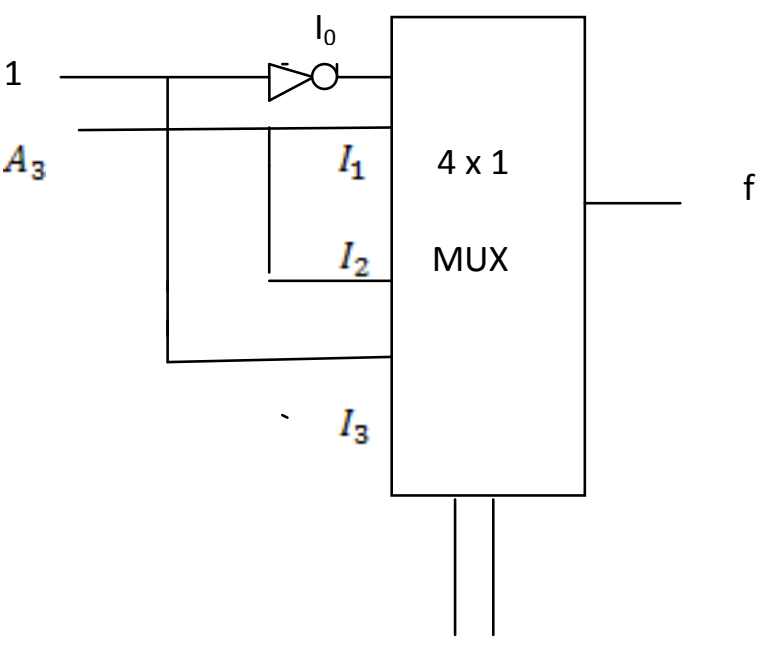

$A_{2} \quad A_{3}$

\subsubsection{4x1 Multiplexer Implementation}

Besides using such inputs, it is possible to connect more complex circuit as inputs to a multiplexer allowing function to be synthesized using a combination of multiplexers \& other logic gates. 


\section{Shannon's Expansion theorem}

Shannon's expansion or the Shannon decomposition is a method by which a Boolean function can be represented by the sum of two sub function of the original. Shannon expansion develops the idea that boolean function can be reduced by means of the identity.

$$
f=x f_{x}+\bar{x} f_{\bar{x}}
$$

where $f$ is any function and $f_{x}$ and $f_{\bar{x}}$ are positive \& negative shannon cofactors of $f$ respectively. A positive shannon cofactor of function $f$ with respect to variable $\mathrm{x}$ is defend as that function with all instances of $\mathrm{x}$ replaced by $1 \mathrm{~A}$ negative shannon co factor is the same, but replaces all instances of $\mathrm{x}$ by 0 .

Any Boolean function $\mathrm{f}\left(\mathrm{A}_{1}, \mathrm{~A}_{2}, \mathrm{~A}_{3},---\mathrm{An}\right)$ can be written in the form

$f\left(A_{1}, A_{2}---A n\right)=\bar{A}_{1}$.f $\left(0, A_{2}, A_{3}^{---A n}\right)+A_{1} f\left(1, A_{2}, A_{3}--\right.$ An)

This expansion can be done in terms of any of the $\mathrm{n}$ variables. as $f\left(A_{1}, A_{2}, A_{3}\right)=\Sigma(3,5,6,7)$

Function can be expressed as sum of products form

$\mathrm{f}=\overline{\mathrm{A}}_{1} \mathrm{~A}_{2} \mathrm{~A}_{3}+\mathrm{A}_{1} \overline{\mathrm{A}}_{2} \mathrm{~A}_{3}+\mathrm{A}_{1} \mathrm{~A}_{2} \overline{\mathrm{A}}_{3}+\mathrm{A}_{1} \mathrm{~A}_{2} \mathrm{~A}_{3}$

It can be manipulated into

$\mathrm{f}=\overline{\mathrm{A}}_{1}\left(\mathrm{~A}_{2} \mathrm{~A}_{3}\right)+\mathrm{A}_{1}\left(\overline{\mathrm{A}}_{2} \mathrm{~A}_{3}+\mathrm{A}_{2} \overline{\mathrm{A}}_{3}+\mathrm{A}_{2} \mathrm{~A}_{3}\right)$

$=\bar{A}_{1}\left(\mathrm{~A}_{2} \mathrm{~A}_{3}\right)+\mathrm{A}_{1}\left(\mathrm{~A}_{2}+\mathrm{A}_{3}\right)$

\begin{tabular}{|l|l|l|l|}
\hline$A_{1}$ & $A_{2}$ & $A_{3}$ & $\mathrm{f}$ \\
\hline 0 & 0 & 0 & 0 \\
\hline 0 & 0 & 1 & 0 \\
\hline 0 & 1 & 0 & 0 \\
\hline 0 & 1 & 1 & 1 \\
\hline 1 & 0 & 0 & 0 \\
\hline 1 & 0 & 1 & 1 \\
\hline 1 & 1 & 0 & 1 \\
\hline 1 & 1 & 1 & 1 \\
\hline
\end{tabular}$>A_{3}$

3.1 Truth table

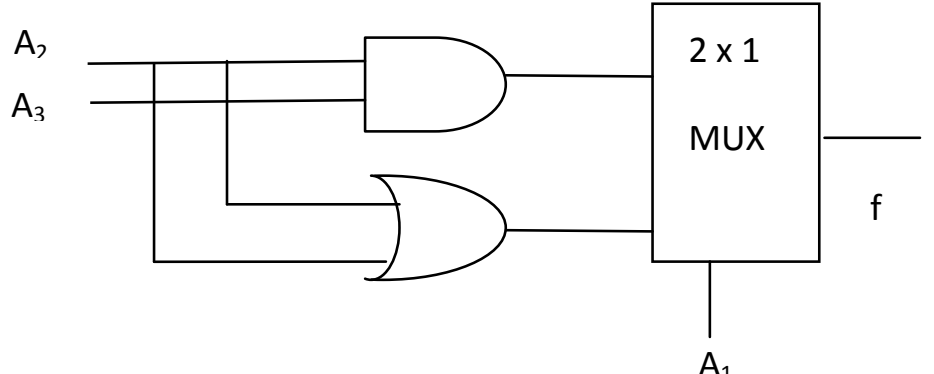

3.2 Truth table Circuit
Three input majority function implemented using a 2 to 1 multiplexer

For three input XOR function

$\mathrm{f}=\mathrm{A}_{1} \oplus \mathrm{A}_{2} \oplus \mathrm{A}_{3}$

$=\bar{A}\left(\mathrm{~A}_{2} \oplus \mathrm{A}_{3}\right)+\mathrm{A}_{1}\left(\overline{\mathrm{A}_{2}} \overline{\oplus \mathrm{A}_{3}}\right)$

\begin{tabular}{|l|l|l|l|}
\hline$A_{1}$ & $A_{2}$ & $A_{3}$ & \\
\hline 0 & 0 & 0 & 0 \\
\hline 0 & 0 & 1 & 1 \\
\hline 0 & 1 & 0 & 1 \\
\hline 0 & 1 & 1 & 0 \\
\hline 1 & 0 & 0 & 1 \\
\hline 1 & 0 & 1 & 0 \\
\hline 1 & 1 & 0 & 0 \\
\hline 1 & 1 & 1 & 1 \\
\hline
\end{tabular}$>A_{2} \oplus A_{3}$

3.3 Truth table

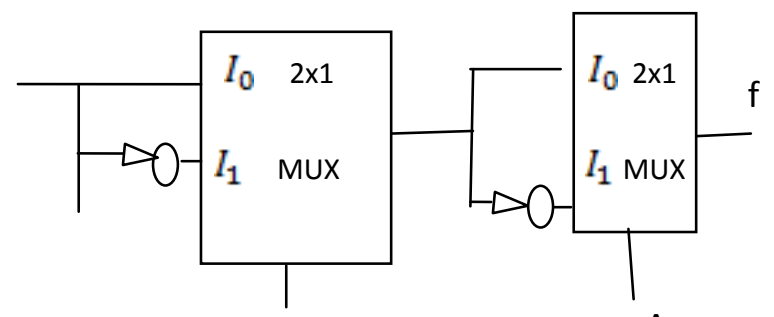

$\mathrm{A}_{2}$

$\mathrm{A}_{1}$

3.4 Three input XOR implemented with

\section{2 to 1 Multiplexer}

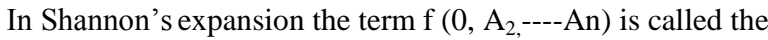
co-factor of $\mathrm{f}$ with respect to $\overline{\mathrm{A}}_{1}$, denoted as $f_{\overline{A_{1}}}$. Similarly the term $\mathrm{f}\left(1, \mathrm{~A}_{2}\right.$------------An)

is called the co-factor of $\mathrm{f}$ with respect to $\mathrm{A}_{1}$, written as $f_{A_{1}}$ , hence

$$
f=\overline{A_{1}} f_{\overline{A_{1}}}+\boldsymbol{A}_{1} f_{A_{1}}
$$


In general if the expansion is done with respect to variable $A_{i}$, then $f_{A_{i}}$ denotes

$$
\begin{gathered}
f\left(A_{1},-----, A_{i-1}, 1, A_{i+1},-----, A_{n}\right) \text { and } \\
f\left(A_{1},----, A_{n}\right)=\overline{A_{i}} f_{\overline{A_{i}}}+A_{i} f_{A_{i}}
\end{gathered}
$$

Complexity of the logic expression may vary, depending on which variable $A_{i}$, is used.

Taking another example, to implement the function $\mathrm{f}=\overline{\mathrm{A}}_{1} \overline{\mathrm{A}}_{3}+\mathrm{A}_{1} \mathrm{~A}_{2}+\mathrm{A}_{1} \mathrm{~A}_{3}$

a) Using 2 to 1 multiplexer, Shannon's expansion using $A_{1}$ gives

$$
\begin{gathered}
f=\overline{A_{1}} f_{\overline{A_{1}}}+A_{1} f_{A_{1}} \\
=\overline{\mathrm{A}} 1\left(\overline{\mathrm{A}}_{3}\right)+\mathrm{A}_{1}\left(\mathrm{~A}_{2}+\mathrm{A}_{3}\right)
\end{gathered}
$$

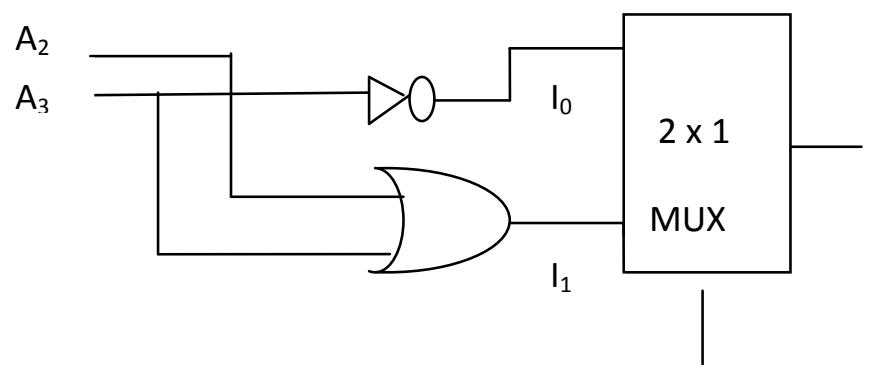

$\mathrm{A}_{1}$
The most commonly used logic block is a lookout table (LUT), which contains storage cells that are used to implement a small logic function. Each cell is capable of holding a single logic value either 0 or 1 . LUTs of various sizes may be created, where the size is defined by number of inputs.

inputs .

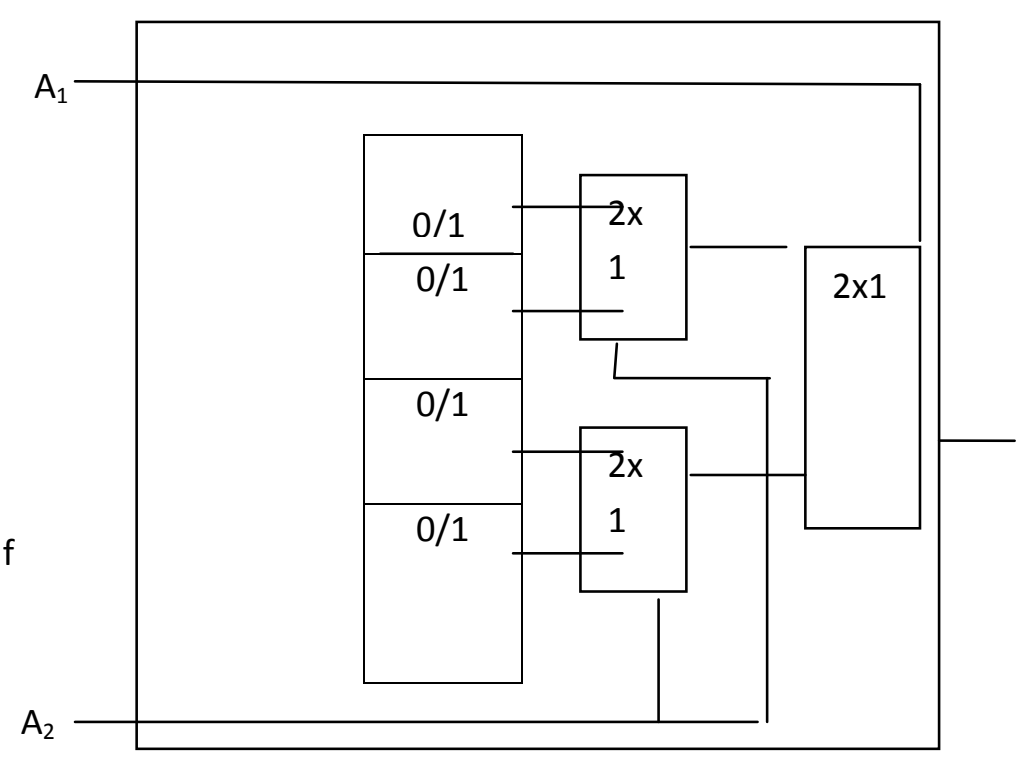

3.7 Circuit for a two input LUT

\subsection{Using 2 to 1 multiplexer}

b) Using 4 to 1 multiplexer, further .using $\mathrm{A}_{2}$ gives

$\mathrm{f}=\overline{\mathrm{A}}_{1} \overline{\mathrm{A}}_{2} \mathrm{f}_{\overline{\mathrm{A}} 1 \overline{\mathrm{A}} 2}+\overline{\mathrm{A}}_{1} \mathrm{~A}_{2} \mathrm{f}_{\overline{\mathrm{A}} 1 \mathrm{~A} 2}+\mathrm{A}_{1} \overline{\mathrm{A}}_{2} \mathrm{f}_{\mathrm{A} 1 \overline{\mathrm{A}} 2}+\mathrm{A}_{1} \mathrm{~A}_{2} \mathrm{f}_{\mathrm{A} 1 \mathrm{~A} 2}$ $=\overline{\mathrm{A}}_{1} \overline{\mathrm{A}}_{2}\left(\overline{\mathrm{A}}_{3}\right)+\overline{\mathrm{A}}_{1} \mathrm{~A}_{2}\left(\overline{\mathrm{A}}_{3}\right)+\mathrm{A}_{1} \overline{\mathrm{A}}_{2}\left(\overline{\mathrm{A}}_{3}\right)+\mathrm{A}_{1} \mathrm{~A}_{2}(1)$
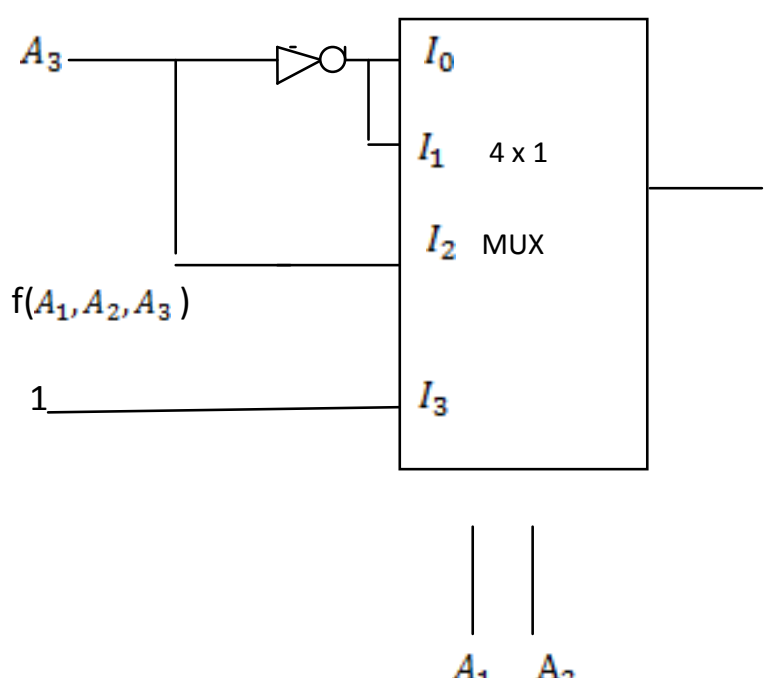

3.6 Using 4 to 1 multiplexer 


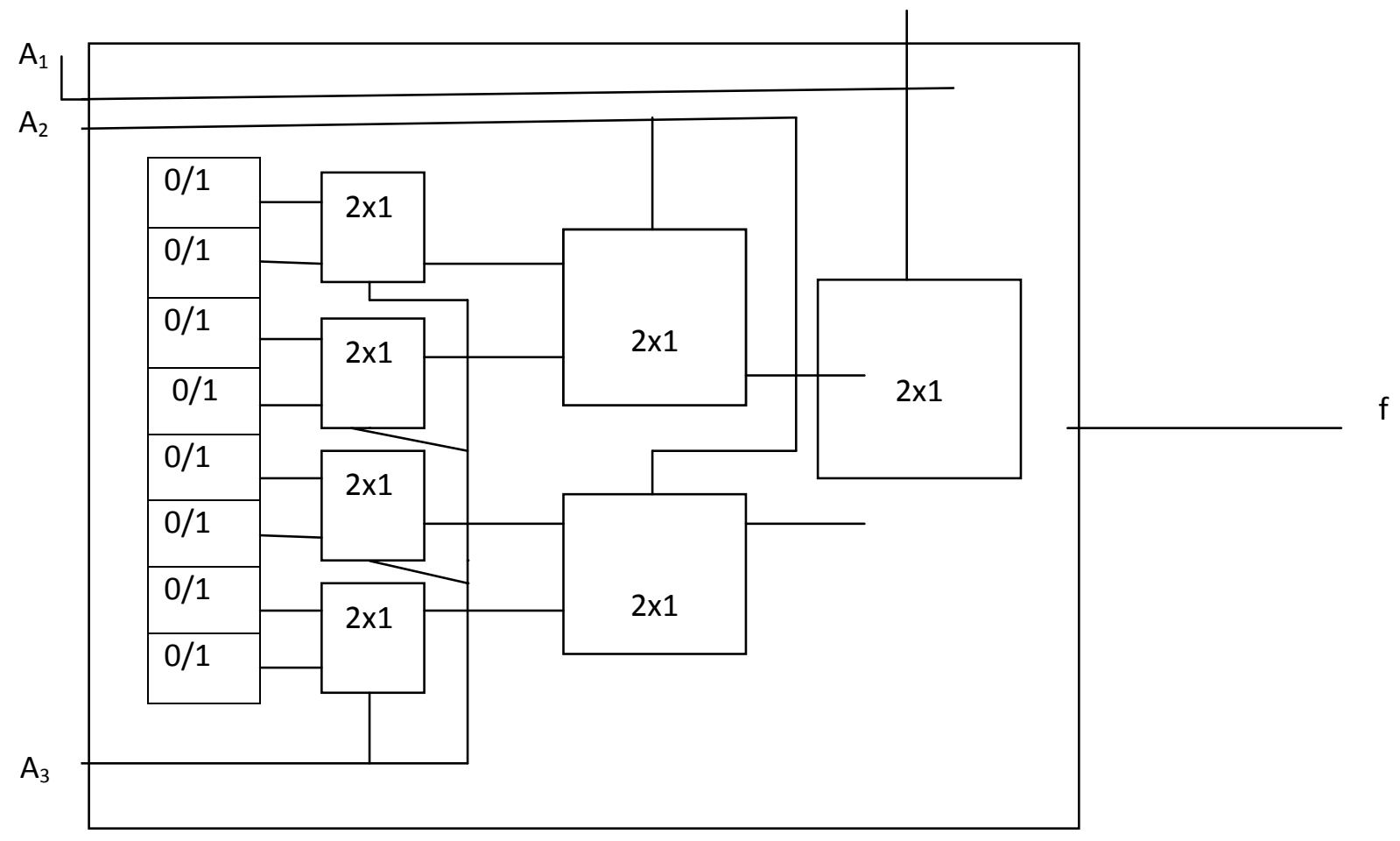

3.8 A three input LUT

Using shannon's expansion any four variable function can be realized with at most three 3 - LUTs (look up tables).

Considering the function

$\mathrm{f}=\overline{\mathrm{A}}_{2} \mathrm{~A}_{3}+\overline{\mathrm{A}}_{1} \mathrm{~A}_{2} \overline{\mathrm{A}}_{3}+\mathrm{A}_{2} \overline{\mathrm{A}}_{3} \mathrm{~A}_{4}+\mathrm{A}_{1} \overline{\mathrm{A}}_{2} \mathrm{~A}_{4}$

Expansion in terms of $\mathrm{A}_{1}$ produces

$$
\mathrm{f}=\overline{\mathrm{A}}_{1} \mathrm{f}_{\overline{\mathrm{A}} 1}+\mathrm{A}_{1} \mathrm{f}_{\mathrm{A} 1}
$$

$=\overline{\mathrm{A}}_{1}\left(\overline{\mathrm{A}}_{2} \mathrm{~A}_{3}+\mathrm{A}_{2} \overline{\mathrm{A}}_{3}+\mathrm{A}_{2} \overline{\mathrm{A}}_{3} \mathrm{~A}_{4}\right)+\mathrm{A}_{1}\left(\overline{\mathrm{A}}_{2} \mathrm{~A}_{3}+\mathrm{A}_{2} \overline{\mathrm{A}}_{3} \mathrm{~A}_{4}+\overline{\mathrm{A}}_{2} \overline{\mathrm{A}}_{4}\right)$

$=\overline{\mathrm{A}}_{1}\left(\overline{\mathrm{A}}_{2} \mathrm{~A}_{3}+\mathrm{A}_{2} \overline{\mathrm{A}}_{3}\right)+\mathrm{A}_{1}\left(\overline{\mathrm{A}}_{2} \mathrm{~A}_{3}+\mathrm{A}_{2} \overline{\mathrm{A}}_{3} \mathrm{~A}_{4}+\overline{\mathrm{A}}_{2} \overline{\mathrm{A}}_{4}\right)$

A circuit with there 3 LUTs that implements this expression

$\mathrm{A}_{1}$

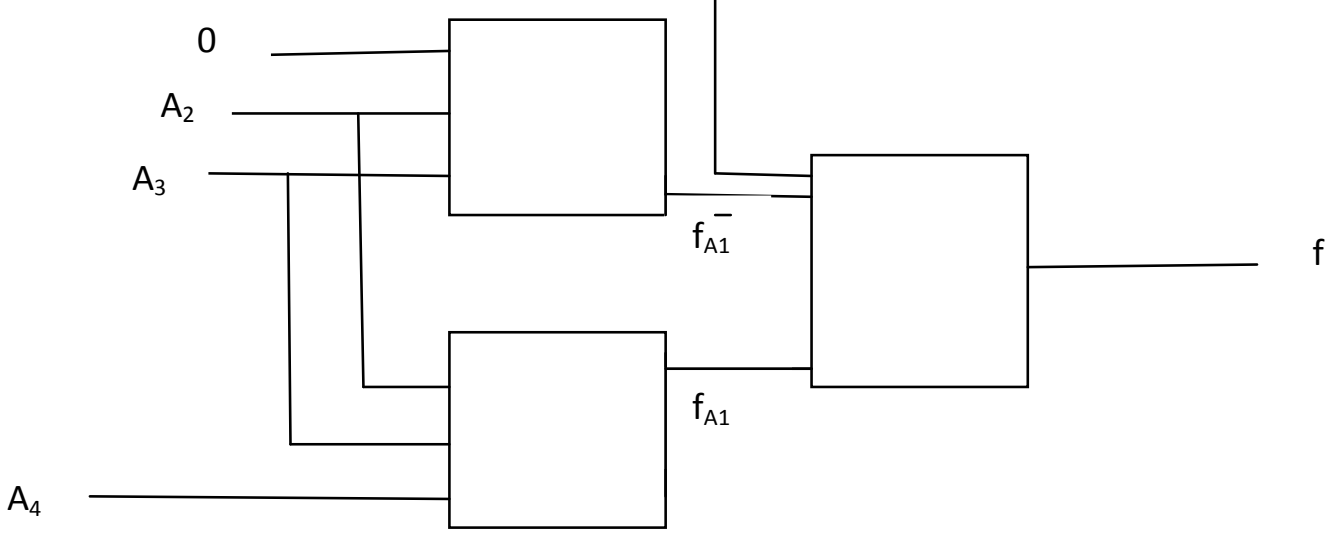

3.9 Using there 3 LUTs 
Decomposition of the function using $\mathrm{A}_{2}$, instead of $\mathrm{A}_{1}$, gives $\mathrm{f}=\overline{\mathrm{A}}_{2} \mathrm{f}_{\mathrm{A} 2}+\mathrm{A}_{2} \mathrm{f}_{\mathrm{A} 2}$

$=\overline{\mathrm{A}}_{2}\left(\mathrm{~A}_{3}+\mathrm{A}_{1} \overline{\mathrm{A}}_{4}\right)+\mathrm{A}_{2}\left(\overline{\mathrm{A}}_{1} \overline{\mathrm{A}}_{3}+\overline{\mathrm{A}}_{3} \mathrm{~A}_{4}\right)$

as $f_{\bar{A} 2}=f_{A 2}$, hence only two 3 LUTs are needed .

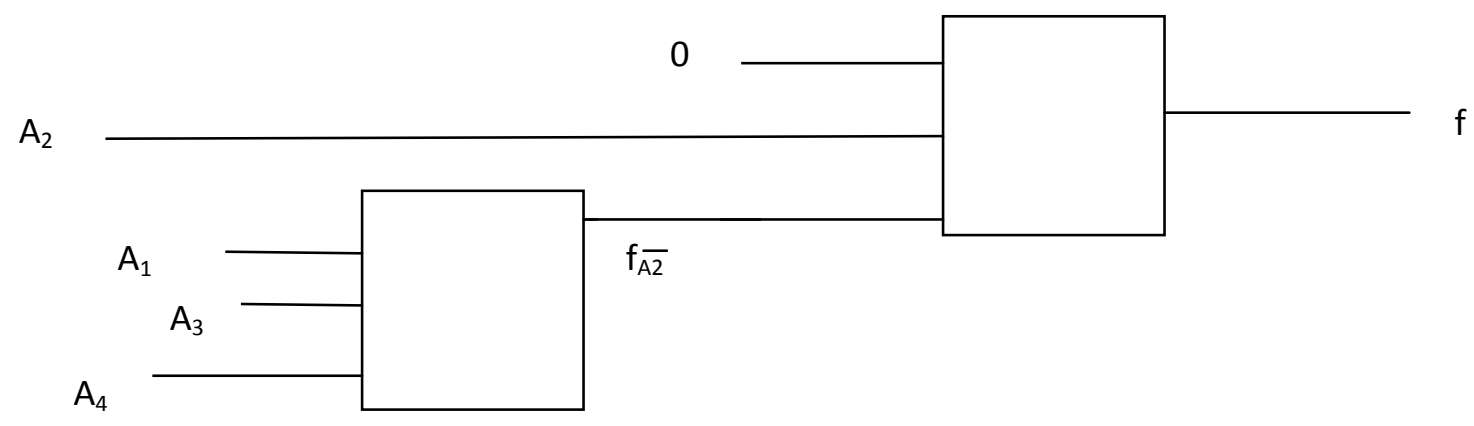

3.10 Using two 3 LUTs.

\section{CONCLUSION}

In this paper we have seen that Boolean functions can be implemented using different multiplexers, $2 \mathrm{x} 1,4 \mathrm{x} 1$ or $8 \mathrm{x} 1$. With the help of Shannon expansion theorem ,complicated Boolean functions can be made easy ,in implementing through multiplexers and LUTs (look up table ),again formed with different combination of multiplexers. This study will be very helpful for researchers and intellectuals to easy understanding and practicing of implementation of Boolean functions through multiplexers in the field of computer science and technology.

\section{REFERENCES}

[1] en.wikipedia.org/wiki/Multiplexer

[2] en.wikipedia.org/wiki/Shannon's_expansion

[3] Arturo Hern'andez Aguirre, Bill P. Buckles, and Carlos Coello Coello. Evolutionary synthesis of logic functions using multiplexers. In C. Dagli, A.L. Buczak, and et al., editors, Proceedings of the $10^{\text {th }}$ Conference Smart Engineering System Design, pages 311-315, New York, 2000. ASME Press.

[4] R. L. Ashenhurst, "The decomposition of switching functions," in Proc.Int. Symp. Theory of Switching Functions, Apr. 1957, pp. 74-116.

[5] Astola, J.T., Stankovi'c, R.S., Fundamentals of Switching Theory and Logic Design, Springer, 2006.

[6] M. MORRIS MANO "Digital Logic and Computer Design" 2nd edition

[7] D. Nasib S. Gill, J.B. Dixit "Digital Design and Computer Organisation" 